\title{
ORIGEN, VARIANTES Y CONTINUIDAD DE UN TIPO ICONOGRÁFICO: EL JUICIO DE PARIS
}

\author{
ORIGIN, VARIANTS AND CONTINUITY OF AN \\ ICONOGRAPHIC TYPE: THE PARIS JUDGMENT
}

\author{
Claudia Campos Colino \\ (Universidad de Málaga, España) \\ claudiacamposcolino@uma.es
}

Recibido: 02 abril 2020 Aceptado: 20 mayo 2020 Publicado: 01 julio 2020

Resumen: El presente trabajo hace un recorrido por algunas de las más importantes fuentes del Juicio de Paris, un mito recurrente a lo largo de la historia del arte occidental que continúa con vigencia en la actualidad. El análisis de estas fuentes, así como un breve repaso de la historia de cada personaje principal nos ayudará a los análisis iconográficos de algunas de las múltiples imágenes que tratan este mito, en un estudio multidisciplinar siguiendo un orden cronológico de las mismas, teniendo siempre como base la transmisión de la tradición.

Palabras clave: juicio, Paris, mitología, iconografía, manzana

Abstract: The Judgment of Paris, a recurrent myth on Art History that continues with the current validity. In order to help the iconographic analysis of these representations, some of the most important sources of the myth have been recognized and analyzed, as well as an approach to the characters. In addition, the work has a motivation to briefly capture the trajectory of history and its representation, basing on the transmission of the tradition.

Keywords: judgment, Paris, mythology, iconography, apple

\section{Introducción}

A grandes rasgos el mito trata de cómo un pastor, Alejandro-Paris, que pertenecía a la familia real frigia sin saberlo, es elegido por Zeus para ser juez en la belleza de las diosas Hera -diosa-reina del Olimpo-, Atenea - diosa de la guerra y la sabiduría- y Afrodita diosa del amor. Este hecho es desencadenado Eris - diosa de la Discordia- en las bodas 
de Tetis y Peleo por no haber sido invitada. Hermes -mensajero de los dioses- es el encargado de acompañar a las diosas y de encomendar la tarea al frigio. Tras analizar las tres propuestas de las diosas -a saber, poder, fuerza militar y amor, respectivamenteganaría Afrodita con la promesa del amor de Helena, mujer de Menelao -rey de Espartae hija de Zeus. Con el paso del tiempo, como estudiaremos a continuación, se añaden más elementos y el más conocido: la manzana dorada, premio para la más bella, lanzada por Eris.

A lo largo de este trabajo, estudiaremos las principales fuentes literarias que nos presentan el mito y, tras un breve resumen de los personajes principales implicados, haremos un somero recorrido de forma cronológica por la historia del arte occidental que ha tratado el tema, desde la antigüedad hasta la actualidad.

\section{Fuentes literarias}

\section{Homero. La Ilíada. s.VIII a.C.}

Ya en La Ilíada de Homero (s.VIII a.C. - Canto XXIV, 25-30) el mito que nos ocupa es mencionado, aunque no descrito como tal, lo que nos lleva a pensar que el mito ya formaba parte en época de Homero del conocimiento colectivo. Así mismo, recae en el Juicio la explicación de por qué Atenea y Hera no estaban en el bando troyano en la contienda, ya que no fueron elegidas por Alejandro como las más bellas.

\section{Ciprias. Ciclo Troyano. s.VII a.C.}

Si avanzamos hasta el s.VII a.C. nos encontramos con Ciprias, los once libros del Ciclo troyano, donde se relata el inicio del conflicto bélico: desde la boda de Tetis y Peleo hasta el inicio de la Ilíada. Este ciclo no nos ha llegado en su totalidad hasta nuestros días, sin embargo, podemos conocer su contenido gracias al autor Proclo en su Crestomatía (s.IV). Aún con la gran diferencia temporal entre ambas obras, sabemos que las escuelas filosóficas no fueron clausuradas hasta el s.VI por Justiniano, con lo que es muy probable que el autor realmente tuviese acceso a estos escritos. En Ciprias, según Proclo, ya se describe el mito, no solo lo menciona. Aparecen más personajes, como Eris y Hermes, y el lugar de los hechos: la boda de Tetis y Peleo. Ciprias solo menciona el ofrecimiento ganador, esto es, el de Afrodita: la mano de Helena. 


\section{Eurípides. Andrómaca y Helena. s.V a.C.}

En el s.V a.C. nos encontramos las menciones de Eurípides en varias de sus obras, de las que destacamos Andrómaca y Helena. La primera nos sitúa después de la Guerra de Troya, cuando Andrómaca - esposa de Héctor- es esclava de Neoptólemo -hijo de Aquiles y Deidamía. En el Coro del Estásimo 1, se apunta al Juicio de Paris como el causante de la destrucción de Troya, y además se nos informa de que Hermes -mensajero de los dioses e hijo de Zeus y Maya- llegó en el carro de los dioses al valle del Ida-donde estaba Paris- y que las diosas se prepararon bañándose en los manantiales, algo que amplía a las Ciprias, que exponía en los fragmentos 4 y 5 la preparación de Afrodita, pero no de todas las diosas. También nos cuenta que las diosas discutían entre ellas durante estos baños y que Afrodita fue la vencedora por lograr embaucar a Paris con sus palabras.

En Helena, concretamente en los versos 30 a 40, Eurípides nos cuenta la versión de ésta una vez pasada la contienda, destacando la envidia de las diosas a su belleza como motivo para su elección como premio.

\section{Ovidio. Las Heroidas. s.I a.C.}

En la Carta XVI -Helena a Paris, cuando este ya es príncipe y va en su búsqueda- hay referencias al Juicio. Se destaca la descripción de la escena, incluyendo detalles más visuales como la presencia de rosas y jazmines, o que las diosas se encontraban desnudas para mostrar su belleza -muy interesante para las representaciones artísticas del mito. También amplía los ofrecimientos de las demás diosas: Juno, reinos y opulencia y Palas, el saber. De nuevo, Helena destaca la posibilidad de la envidia de Venus a su belleza, y además pone en entredicho el crédito que le dieron las diosas a Paris como juez de sus bellezas, siendo un hombre de mente pobre. Así mismo, la consideración de Helena sobre todos los demás dones hace encarnar en su figura todos ellos, dándole peso a su figura.

En la Carta V -Enone a Paris, ninfa esposa de este antes del Juicio. Eurípides, en voz de Enone, nos cuenta aquí sin embargo una versión distinta, donde Venus y Juno no se encontraban desnudas, solo Minerva-Palas, quien además portaba armas. Es la primera fuente literaria que nos habla del miedo que pasó Alejandro al ser elegido juez, no así la primera fuente artístico-plástica. 
Higinio. Fábulas. s.I a.C. - I d.C.

No será hasta la época helenística cuando aparezca el atributo más conocidos del mito: la manzana arrojada por Eris, la discordia. Higino, en su Fábula 92, ya la menciona, así como el motivo de Eris para estar tan enfurecida: no fue invitada por Júpiter a la boda de Tetis y Peleo. Por ello lanzó desde la entrada de la boda al centro una manzana y dijo no llevaba inscripción alguna- que era para la más bella, poniendo en primer lugar a Júpiter en el aprieto de decidir, lo cual sabemos que no asumió.

\section{Apolodoro. Biblioteca mitológica. s.I}

También en el s.I encontramos referencia en la Biblioteca mitológica de Apolodoro, en el epítome III, 1-2. Éste no nos amplía información en cuanto al desarrollo de los hechos, pero si lanza dos teorías interesantes a las razones de Zeus para provocarlo: por un lado, pudo ser para dar ocasión a los semidioses de brillar o bien, para dar fama a su hija Helena.

\section{Luciano. Diálogo de los Dioses. s.II}

En el s.II nos encontramos un desarrollo muy amplio y destallado del mito en el Diálogo de los dioses de Luciano, en concreto, en el Juicio de las Diosas (cap. 20). Se nos habla de varias cuestiones hasta ahora no tratadas, como el motivo de la elección de Alejandro como juez -por ser de bello y experto en el amor, además de tener sangre real-y el rechazo de Zeus a tal papel -por tenerles el mismo afecto a las tres diosas (aunque él mismo sentencia que no todas son igualmente bellas posteriormente) y por no querer enemistarse con las no vencedoras. Según Luciano, Afrodita y Atenea, comenzarían su plan de soborno al frigio en el viaje al Ida, intentando sacar información sobre su juez a Hermes.

Es aquí cuando ya se nos habla de la manzana con inscripción. También se vuelve a hablar del miedo de Paris ante tal papel, aunque disfruta también del mismo ya que las diosas, según la obra de Luciano, se desnudaron a petición del mismo. Paris las contemplaría en conjunto y después en separado, en orden: Hera, Atenea y Afrodita. Afrodita se gana su favor no solo con la belleza de Helena sino ensalzando el ego de Alejandro, ya que le dice que él merece mucho más de lo que tiene. Así mismo, no solo 
le promete a Helena sino su guía en el rapto de ella junto a Amor y a Deseo, a las Gracias, la Pasión y a Himeneo, dios del matrimonio.

\section{Apuleyo. s.II}

También en el s.II encontramos a Apuleyo, quien describe una obra de teatro a la que él asistió sobre el Juicio de Paris. Esta fuente bien podría ser situada en el recorrido artístico del mismo y, de hecho, Elvira Barba lo pone en relación al mosaico de Antioquía y a las arquitecturas efímeras (Elvira, 2008, p.450), ya que habla de la escenografía de la obra se había fabricado un monte de grandes dimensiones de madera adornado con árboles naturales y una fuente de la que salía agua en su cima, además de incluir cabras pastando.

Menciona también el vestuario de los personajes; Alejandro, con una túnica femenina, manto oriental y tiara de oro; Hermes, desnudo con una clámide en su hombro izquierdo, pequeñas alas en su cabeza y el caduceo; Juno, con diadema y cetro; Minerva, con escudo, lanza, casco y corona de olivo; Venus, desnuda con gasa azul en sus partes pudendas.

Por primera vez, se dice que la manzana llevaba láminas doradas. Además, esta obra de teatro añadía personajes a la escena: el séquito de cada una de las diosas. Juno aparecía acompañada de Castor y Polux, con música de flauta jonia; Minerva, con el Terror y el Miedo, con un canto guerrero y flauta en tono dorio; y Venus con niños -a modo de Cupidos-, las Gracias y las Horas, con melodías lidias.

\section{Iconografía de los personajes principales}

\section{Paris}

Desde el periodo arcaico hasta final del imperial, suele aparecer con aspecto juvenil y un instrumento de cuerda, como explica Elvira Barba, aunque también puede llevar barba en el s.VI. a.C. Desde el s.IV a.C. se normaliza su representación vestido a la oriental. En periodo neoclásico, como nos explica Hall, es común su aparición con el gorro frigio. 


\section{Hermes}

Suele ser un personaje que aparece como mensajero y no como protagonista. Sus primeras apariciones reconocibles en el arte se remontan al s.VII a.C. (Elvira, 2008, p.218). Aparece entonces con barba hasta su pérdida en el s.VI a.C. En el periodo arcaico es representado como los embajadores de la época - pelo largo y sobrero triangular con pico sobre su frente. Aparece normalmente con botas rematadas en espiral y aladas -por su velocidad- y el caduceo -objeto que cambió a Apolo por la flauta. A partir del s.VI a.C. su imagen se acerca a la conocida en el Clasicismo: se pierde la barba y la melena, se cambia el sombrero por el pétaso, casquete o simplemente, con la cabeza al descubierto, se simplifican las botas y se elabora más el esquema del caduceo. Como Mercurio en Roma, se representa joven e imberbe, aparece el marsupio para las monedas, las alas en el pétaso, y en ocasiones, serpientes en el caduceo y pérdida del calzado pasando las alas a los pies. También puede ser encontrado con el falo.

\section{Hera}

En sus primeras representaciones era confundida con otras diosas como Demeter, sobre todo entre los ss. VIII y VI a.C. Puede aparecer sentada o de pie, vistiendo el peplo y tocada con polos. Puede aparecer con un niño en brazos o junto a una pátera, ya que es símbolo de la mujer y la femineidad, así como encarnación del ciclo de la vida femenina: virginidad, matrimonio, parto y viudez. A partir del s.VI a.C. ya se conoce como esposa de Zeus, esto es, Diosa del Olimpo, con lo que empiezan a incluirse símbolos de realeza. En época clásica y helenística, aparece normalmente con túnica en vez de peplo y manto, corona o diadema regia y velo nupcial. Sigue apareciendo en esta época con cetro y pátera a lo que se le suman flores y frutas, símbolos de juventud y fecundidad. Al cuclillo, que aparecía anteriormente, se le suma el pavo real en el Helenismo, quizás por el contacto entre Grecia e India, además de por el pasaje de Ío, que aparece en las Metamorfosis de Ovidio. Suele acompañarse, además, del helicriso, la granada y el lirio. En Roma se asimila como Juno, diosa preexistente cuyo nombre significa juventud.

\section{Atenea}

Era diosa de la casa en época prehelénica, por ello unos de sus atributos son las serpientes, que simbolizan el asentamiento doméstico sobre la Tierra (Elvira, 2008, p.203). También 
la vista y la lechuza, que vela el sueño de los moradores. Es en periodo micénico cuando se convierte en hija de Zeus, pasando de la protección de la casa a la protección del palacio y el monarca, defendiendo la acrópolis y castillos micénicos y siendo consejera de reyes y jefes militares. Se convierte en diosa virgen al no aceptar el dominio de nadie, armada y sabia -la fuerza y la prudencia son dos de las virtudes de los buenos monarcas. En el s.VIII a.C. aparece vestida con peplo, escudo, lanza y en ocasiones casco. En el s.VI a.C. se le añade la égida, con protección mágica, regalo de Zeus por su nacimiento y la cabeza de Medusa, regalo de Perseo. Puede aparecer, además, con el olivo - por su disputa con Poseidón- y la pátera -para ofrecer alimento y bebida a los héroes.

\begin{abstract}
Afrodita
Diosa del amor, del deseo sexual, protectora del matrimonio y los jardines, sobre todo en su encarnación como Venus. Se suele representar junto a niños y animales, sobre todo la paloma. Aunque aparece en muchas ocasiones desnuda, también puede aparecer con vestimentas, muy recargadas en Chipre. El peplo es cambiado por la túnica en el s.VI a.C. y aparece también con corona cilíndrica y polos. Además de la manzana dorada, ganada en el juicio, también puede aparecer con otras frutas, como la granada (fertilidad), con flores y objetos de tocador. Desde este siglo, además, puede aparecer acompañada de su hijo Eros.
\end{abstract}

\title{
Repercusión artística del mito: de la antigüedad a la actualidad
}

\section{Antigüedad}

Ya en la Antigüedad, es un mito ampliamente representado, apareciendo en vasos griegos desde el s.VII a. C. hasta llegar a los sarcófagos romanos. En las primeras representaciones, el personaje de Paris es representado con cierto temor, aunque su gesto se irá relajando con el tiempo.

En las cerámicas áticas de figuras negras, la representación suele tener un carácter más estático que en las de figuras rojas, quizás por el requerimiento de la técnica. En las de figuras negras, la escena se suele limitar a un desfile de diosas, casi sin identificar a excepción de Atenea (casco, égida y lanza), presidido por Hermes. Sin embargo, las de figuras rojas -en especial las copas y las hidrias-desarrollan más la calidad escenográfica 
del mito, dotando ya a las diosas con algunos de sus atributos. Ejemplos de todo ello los encontramos en el Juicio de Paris del ánfora ática de figuras negras del British Museum de Londres (540 - 350 a.C.) [1] en contraste con las hidrias áticas de figuras rojas del pintor del enócoe de Yale (ca.470 a.C.) y del pintor de Paris de Carlshue (ca.400 a.C.) [2]. "Ninguna diosa, en el arte griego, se destapaba, y sólo en Época Romana surge, de forma incipiente, la desnudez de Afrodita, ya por entonces [era] normal en sus imágenes representativa" (Elvira, 2008: 449). Sin embargo, Paris sí podía aparecer desnudo. Vemos como el mito es de gran interés para los ceramistas áticos, extendido después a los talleres itálicos.

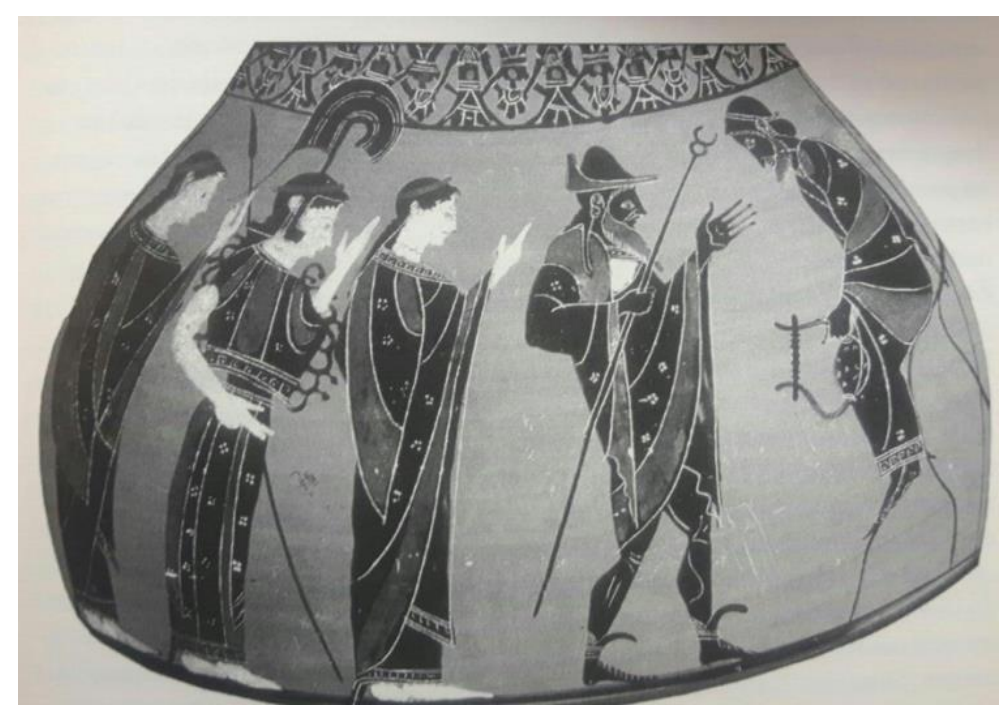

1. Juicio de Paris. Ánfora ática de figuras negras. 540 - 350 a.C. British Museum, Londres

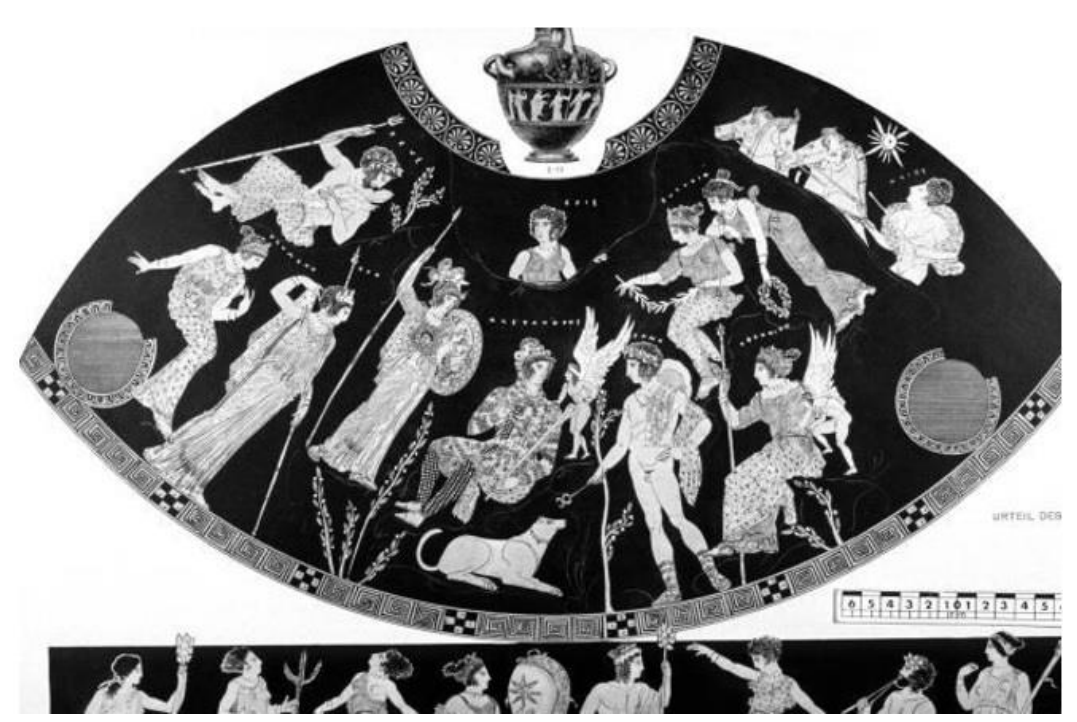

2. Hidria ática de figuras rojas. Pintor del Paris de Carlshue. c. 400 a.C 
En el Mosaico de Antioquía (115 - 150 d.C.) conservado en el Museo del Louvre, Paris aparece en un entorno natural parecido al que describe Grimal: "representábase a Paris como un pastor, en un escenario silvestre, junto a una fuente" (Grimal, 1984, p. 409). Está acompañado de una columna votiva con una estatua de lo que puede ser una ninfa (Elvira, 2008, p. 631). Aparece Hermes, con alas en la cabeza y caduceo, y las tres diosas vestidas. Afrodita está acompañada de su hijo Eros y vestida de blanco, Atenea armada con escudo, lanza y casco y Hera con ropas lujosas por su estatus olímpico. Toda la imagen se asemeja a la descripción de Apuleyo.

En Andalucía también tenemos ejemplos de la época tratando el Juicio: el Mosaico de los amores (96 d.C. Antigua Cástulo, hoy Linares, Jaén) y el Mosaico de Casariche (426 - 500 d.C. en Sevilla). En ambos, al contrario que en el de Antioquía, ya se muestra a Afrodita desnuda.

\section{Edad Media}

En la Edad Media, como explica Elvira Barba, el mito no tiene profusión artística, aunque si pervive el significado de las tres diosas que lo componen - poder, éxito militar y amoren la literatura alegórica. El mito llega a la literatura medieval gracias a las traducciones latinas de los textos de Dares y Dictis sobre la Guerra de Troya (Moormann y Uitterhoeve, 1997, p. 261).

Se utilizará de una forma moralizante, tanto en esta época como en la Edad Moderna, donde Paris y Helena serán culpables de la Guerra de Troya. Lo vemos, por ejemplo, en Ovide Moralisé (s.XIV) o en Crónica General y General Estoria de Alfonso X (s.XIII), como pasaría con otros temas en la emblemática.

\section{Edad Moderna}

Será en el Renacimiento cuando el Juicio volverá con fuerza a las representaciones artísticas, en primera instancia, con las vestimentas de la época: G. de Benvenuto (ca.1510) y Lucas Cranach (ca.1528), representando un orbe en lugar de la manzana.

A partir de Rafael (s.XVI), el mito volverá a la visión clasicista. Su fresco, hoy desparecido, que conocemos a través del grabado de Marcantonio Raimondi [3], influye sobre todo en la representación de las diosas desnudas de forma casi sistemática a partir 
de entonces. En el grabado encontramos a Paris con el gorro frigio a la izquierda, desnudo y acompañado de un perro y un bastón de pastor. Entrega la manzana a Afrodita, acompañada de Eros. Hera aparece con el pavo real y Atenea nos da la espalda, con su casco en el suelo. Hermes aparece con el caduceo rematado en serpientes y el pétaso. Zeus se encuentra en las escenas superiores, junto al águila y a Artemisa. La Victoria, alada, corona a Afrodita.

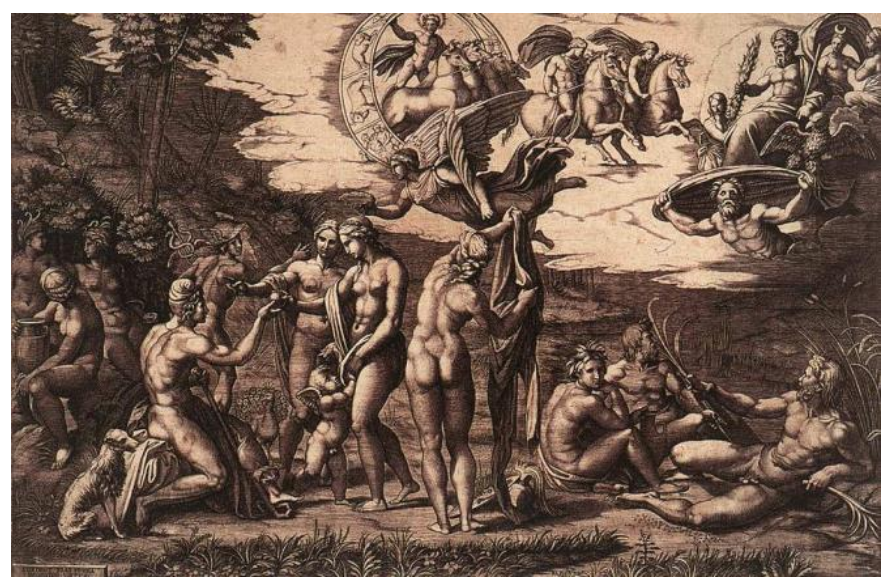

3. Juicio de Paris. Grabado de Marcantonio Raimondi reproduciendo el fresco perdido de Rafael.

$$
\text { Ca.1515 }
$$

Pero no es solo en las artes plásticas un motivo recurrente en este siglo, también en las artes decorativas. Y es que su temática era especialmente atractiva para arcones de novia o fuentes de Urbino y Faenza, ya sea como expresión de la moral vigente o como excusa para pintar tres desnudos femeninos en distintas posiciones.

Rubens le dedicó varias obras al tema, representando momentos distintos de interés. Aunque la más conocida la versión de 1638 conservada en el Museo del Prado encargo de Felipe IV para la decoración del Palacio del Buen Retiro-, la obra realizada en 1632 es más rica en presencia de atributos y la de 1557 es la única en la que aparecen otros personajes, como lo dioses fluviales.

El mito también llegó a la ópera. Il pomo d'oro se produciría con ocasión de la boda de Leopoldo I y Margarita de España en 1666, con música de Cestis y libreto de Sbarra. Continuaron, también, las parábolas moralizantes como La manzana de la discordia y robo de Elena de Mira de Maescua y Guillén de Castro (ca.1618) y El robo 
de Elena y destrucción de Troya de Rojas Zorrilla (s.XVII). En ellas la simbología propuesta era Paris-demonio, Elena-alma y Menelao-Cristo.

Llegando al s.XVIII crece el interés por los temas colindantes, como los preparativos de Afrodita, de los que nos hablaban las Ciprias, por Boucher (1703-1770), o Watteau (1718) representando el momento en que Paris da la manzana a una Afrodita desnuda, protagonista de la obra.

Sin embargo, también existen otros tratamientos en este siglo, como el que hace el neoclásico Mengs (1756) en la que resulta interesante la figura del sátiro tras un árbol en las penumbras, a modo de voyeur, dándole el carácter de marcado erotismo que tienen, no solo las representaciones del Juicio desde el Arte Romano, sino también en las fuentes desde ese momento, como ocurre con el Diálogo de los dioses de Luciano (s.II).

\section{Edad Contemporánea}

El s. XIX nos deja obras tan personales como el propio arte de la época. Desde Flaxmann (1755-1826) a William Blake (1811), pasando por Moreau (1852), Feuerbach (1870), von Marées (1881) y Klinger (1887).

En el s.XX, podemos confrontar las obras de Gauguin (1903) -quien representa a las diosas como campesinas, influencias de su estancia en Tahití, solo distinguibles por la presencia del pavo real y el personaje alado- y Renoir (ca.1914) -que mantiene la tradición, aunque las diosas aparecen sin atributos.

También cabe destacar las obras de Simonet Lombardo (1904) y Sargent (ca.1920) [4], realizando el primero en una escena terrenal, mientras que el segundo apuesta por un tratamiento celestial del mito. Sargent diferencia la figura humana de Paris de la de las diosas, quienes son representadas como si de esculturas clásicas se tratase.

No me gustaría acabar mi pequeño recorrido sin mencionar a Eleanor Antin (2007) y a Mary Ellen Croteau (2006) [5]. La primera por recoger, en la actualidad, los arquetipos de cada uno de los personajes de una forma brutalmente entendible para nuestro conocimiento colectivo sin la pérdida de la tradición y la segunda, por su mensaje subversivo, en el que el juez es ahora juzgado por las diosas, una crítica al papel secundario de la mujer en el arte, como objeto al que visualizar y juzgar. 


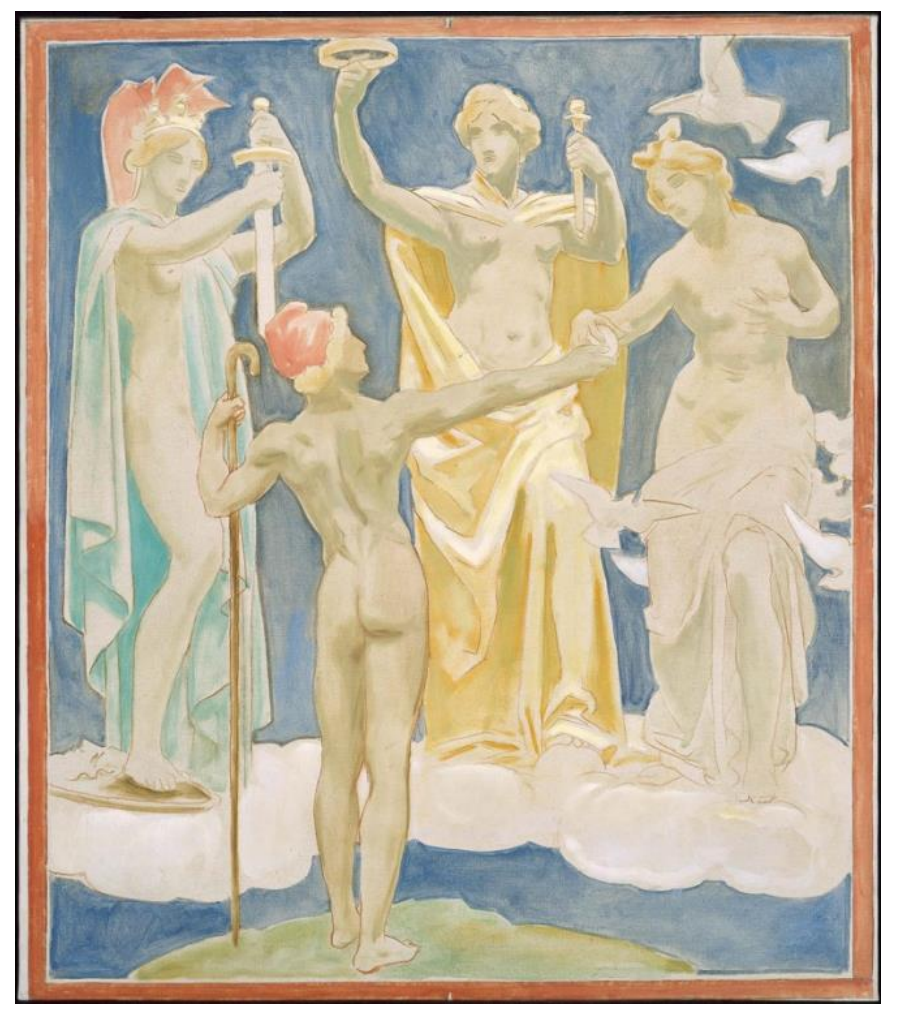

4. Juicio de Paris. J. S. Sargent. Ca. 1920. Museo de Bellas Artes de Boston. 77,47 x 67,63 cm. Óleo sobre lienzo

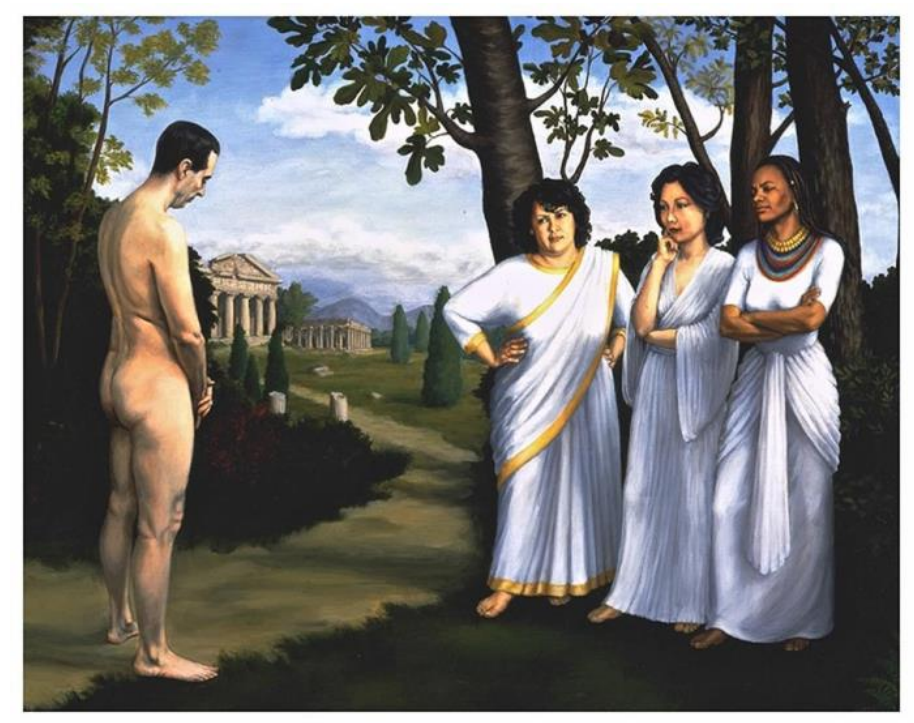

5. Juicio de Paris. Mary Ellen Croteau. 2006

\section{Conclusiones}

Podemos destacar que hay, a grandes rasgos, dos modelos de representación que parten de la Antigüedad. Uno sería el de la inclusión de muchos personajes adyacentes y otro, el 
de la representación de los personajes principales aquí expuestos. Entre estos dos modelos, podemos concluir que es el segundo el que llega hasta nuestros días.

En la actualidad, se utiliza la iconografía del mito de una forma mucho más amplia, incluso subvirtiendo e incluso obviando el mensaje tradicional -lo cual también sería digno de estudio.

Tras la realización del estudio, en cuanto a la vigencia de la mitología clásica, no solo en el arte sino en el imaginario colectivo actual, bien podría citarse a Carl Jung: "el alma contiene todas las imágenes de que han surgido los mitos y que nuestro inconsciente es un sujeto actuante y paciente, cuyo drama el hombre primitivo vuelve a encontrar en todos los grandes y pequeños procesos naturales” (Jung, 1994, p.13).

\section{Referencias bibliográficas}

Apolodoro (1987). Biblioteca mitológica. Ed. de José Calderón Felices. Akal: Madrid. Apuleyo (1988) El asno de oro. Ed. de Francisco Pejenaute Rubio. Akal: Madrid.

Bernabé, Alberto (1979). Fragmentos de épica griega arcaica. Gredos: Madrid.

Bremmer, Jan (2006). La religión griega. Dioses y hombres: santuarios, rituales y mitos. Trad. Lautaro Roig Lanzillotta. Ed. El Almendro: Córdoba, Ed. El Almendro.

De Samosata, Luciano (1963). Diálogos de los muertos; Diálogos de los dioses; Diálogos de los dioses marinos. Ed. de F. García Yagüe. Aguilar: Madrid.

Diaz, Matías (1975). Museo del Prado: catálogo de pintura: escuela flamenca. Museo del Prado: Madrid.

Elvira, Miguel Ángel (2008). Arte y mito. Manual de iconografía clásica. Silex: Madrid. Eurípides (1992). Tragedias I. Ed.y trad. de Juan Antonio López Férez. Cátedra: Madrid. Fernández, María Cruz (2020). La guerra de Troya: imágenes y leyendas. Alderabán: Madrid.

Gallardo, María Dolores (1985). Manual de Mitología Clásica. El. Clásicas: Madrid. Grimal, Pierre (1984). Diccionario de mitología griega y romana. Paidón: Barcelona. 
Hall, James (1987). Diccionario de temas y símbolos artísticos. Alianza Editorial: Madrid.

Higinio (2009). Fábulas. Ed. de J. del Hoyo. Gredos: Madrid.

Homero (1989) Ilíada. Ed. de C. Rodriguez Alonso. Akal: Madrid.

Jung, Carl (1994) Arquetipos e inconsciente colectivo. Paidós: Barcelona.

Mancilla, Cristian (2016), “Crisis en Troya. Paris $<<$ el juez $>>$ visto por los griegos”, Revista Europa, n. ${ }^{\circ}$ IX, pp. $75-89$.

Moormann, Eric M. y Uitterhoeve, Wilfried (1997). De Acteón a Zeus: temas de mitología clásica en literatura, música, artes plásticas y teatro. Akal: Torrejón de Ardoz. Morales, José Luis (1986). Diccionario de iconología y simbología. Ed. Taurus: Madrid. Ovidio (1884). Las Heroidas. Luis Navarro Editor: Madrid.

Pitarch, Antonio José et al. (1982). Fuentes y documentos para la Historia del Arte. Arte Antiguo. Ed. Gustavo Gili: Barcelona.

Price, Simon. y Kearns, Emily (2003). The oxford dictionary of classical myth \& religion. Oxford University Press: Nueva York.

Ripa, Cesare (1987). Iconología I y II. Akal: Madrid.

VV.AA. (1985). Museo del Prado: catálogo de las pinturas. Museo del Prado: Madrid.

Woodford, Susan (2003). Images of myths in classical antiquity. Cambridge University Press: Cambridge. 